\title{
Algunas reflexiones sobre la escritura de la historia del Tahuantinsuyo a partir de fuentes primarias (quipus)
}

\author{
GARY URTON
}

\section{Resumen}

Se plantea cómo deberíamos repensar la naturaleza y el contenido de la información "histórica» contenida en los quipus y, a partir de esta nueva forma de acercarnos al contenido de estos artefactos, cómo me parece que podríamos escribir una historia del Tahuantinsuyo basada en fuentes primarias, materia sobre la que Sabine MacCormack escribió importantes ensayos con deslumbrante erudición. En pocas palabras, mi argumento es que la mayor parte de la información contenida en los quipus se refiere a estadísticas administrativas; por lo tanto, si repensamos la naturaleza de la historia -esto es, que ella no se ocupa de grandes hombres y batallas importantes, sino más bien de la economía, la demografía y la relación que la sociedad mantiene con el medio ambiente-, podremos efectivamente escribir una historia indígena del Imperio Inca. 
Palabras clave: Tabuantinsuyo, quipus, historia indígena, Imperio Inca

\section{Abstract}

A possible redefinition of nature and content around Khipus «historical» information is revealed as a new way to approach the substance of these knotted textile record-keeping devices used by the Inkas. This article aims to reveal how a new history of Tawantinsuyu based in primary data can be written. This is the world about which Sabine McCormack wrote relevant essays with extraordinary erudition. In short, my argument defends that main khipus information refers to administrative or official statistics; so we'll be able to write a real indigenous history of the Inka empire, specially if we redefine History, that is, if History is consists of more than just great men and great battles, if History can be written as a memory relationship of Economy, Demography and Society with NaturalEenvironment.

KeYwords: Tawantinsuyu, Khipus, Indigenous History, Inka Empire

UNO DE LOS TEMAS sobre los cuales mi querida y llorada amiga Sabine MacCormack escribió con deslumbrante erudición concernía a cómo y desde qué perspectiva se escribieron las historias más tempranas del Tahuantinsuyo («las cuatro partes íntimamente unidas»), el nombre que los incas le dieron a su imperio. Fue en su último trabajo, On the Wings of Time: Rome, the Incas, Spain and Peru (2007), donde se ocupó de este tema con profundidad, del modo más exhaustivo y con gran perspicacia. En este libro, que es un trabajo de extraordinaria erudición, MacCormack examinó detenidamente la cuestión de cómo fue que se escribieron las historias más tempranas del imperio inca, esto es quiénes las escribieron, qué fuentes usaron y qué perspectivas adoptaron con respecto no solo a cuestiones tales como la historia de sus reyes, reinas y los grandes eventos definidores del Tahuantinsuyo, sino también de cómo 
fue que su historia fue comprendida por dichos autores como parte de una historia universal. Esto último hace referencia explícita a los esfuerzos realizados por los primeros historiadores del Tahuantinsuyo -v.g. Cieza de León, Pedro Pizarro, Las Casas, Sarmiento de Gamboa y (posteriormente) Garcilaso de la Vega- para integrar la historia inca dentro de la historia providencial divinamente dirigida de la cristiandad occidental. Las cuestiones centrales en lo que respecta a la relación del Tahuantinsuyo con la historia del cristianismo eran dos: ¿cómo hacer que la existencia de pueblos andinos (y de un Nuevo Mundo) calzara con la creación de la humanidad en un único acto divino obra de Dios en el Jardín del Edén? ¿Y qué papel tuvo la divina providencia en la conquista española de los incas? Gracias a su profundo conocimiento de la literatura clásica y patrística de Occidente, el examen que MacCormack hiciera de estas y otras cuestiones afines es el más perceptivo, informado y autorizado que se hubiera escrito jamás sobre estos importantes y complejos temas.

$\mathrm{Al}$ inicio de $\mathrm{On}$ the Wings of Time, MacCormack deja en claro que la razón por la cual cuando nos ocupamos de la historia del Tahuantinsuyo nos vemos obligados a realizar exámenes tan complejos de las obras de historiadores y teólogos de Europa occidental, es porque no contamos con relaciones de primera mano producidas por los mismos escribas incas, no hay inscripciones indígenas anteriores a la conquista que expresen lo que los incas sabían y pensaban de su propia historia. Nos vemos, por ello, forzados a depender de lo que los primeros españoles -que prepararon las primeras relaciones escritas acerca de la vida y el pensamiento en los Andes a partir del choque inicial de estas dos civilizaciones que tuvo lugar en Cajamarca en 1532- dijeron de la naturaleza y la historia de los incas. Señala que las únicas fuentes primarias andinas con que contamos, a partir de las cuales tal vez algún día puedan construirse historias indígenas, son los quipus (del quechua khipus, «nudo»), registros en cordeles anudados. Estos fueron los principales implementos usados por las autoridades incas para registrar información 
-v.g. censos, registros del tributo y otros asuntos administrativos e históricos- referida al imperio inca desde antes de la invasión española (Figura 1).

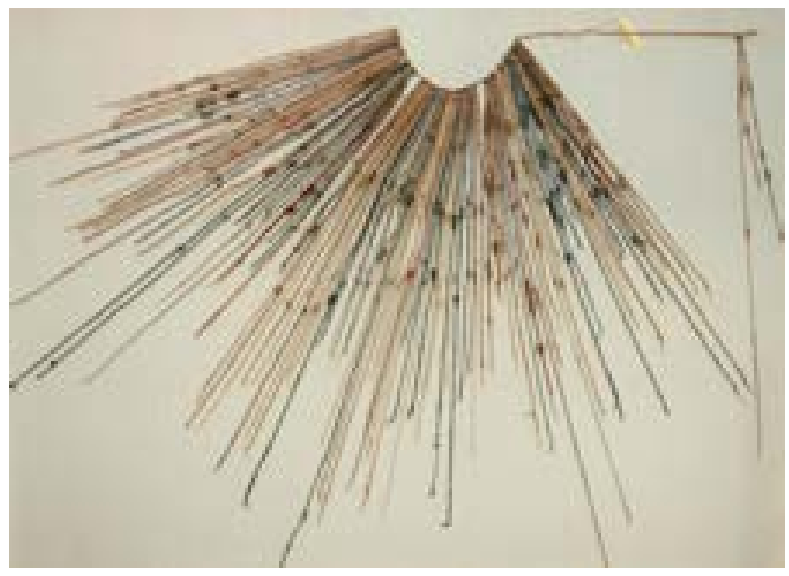

Figura 1. Un quipu inca.

Centro Malqui, Leymebamba, Perú. Fotografía del autor.

Aunque a lo largo del siglo XX, los quipus fueron objeto de un intenso estudio por parte de unos cuantos investigadores dedicados, ${ }^{1}$ hasta la fecha no hemos tenido éxito en «descifrar» estos registros en forma tal que haga que su contenido sea legible y accesible al público en general. Debido a esto, MacCormack y cualquier otro historiador o antropólogo que desee escribir acerca de la historia inca, se ha visto obligado a depender de las crónicas hispanas escritas después de la conquista, las cuales son su fuente principal para dichas historias. Habiendo estado yo mismo profundamente involucrado en el estudio de los quipus desde comienzos de la década de 1990 (Urton 2003; 2017), quisiera sugerir aquí, en primer lugar,

1 Debo mencionar a Locke (1923); Ascher y Ascher (1997); Pereyra (2006). Son especialmente relevantes los estudios recopilados en Curatola y De la Puente (2013). 
que tal vez hemos estado pensando la «historia» en formas que son del todo incompatibles con la información contenida en ellos; $y$, en segundo lugar, que si repensamos y volvemos a imaginar qué podría constituir una historia, al menos en lo que a los incas concierne, tal vez estaríamos en condiciones de construir, hoy, una historia del Tahuantinsuyo basada en estas frágiles fuentes primarias contenidas en cordeles anudados.

Aquí voy a presentar en líneas generales cómo me parece que deberíamos volver a pensar la naturaleza y el contenido de la información «histórica» contenida en los quipus y, a partir de esta nueva forma de acercarnos al contenido de estos artefactos, indicar cómo me parece que podríamos escribir una historia del Tahuantinsuyo basada en fuentes primarias. En pocas palabras, mi argumento es que la mayor parte de la información contenida en los quipus se refiere a estadísticas administrativas; por lo tanto, si repensamos la naturaleza de la historia - esto es, que ella no se ocupa de grandes hombres y batallas importantes, sino más bien de la economía, la demografía y la relación que la sociedad mantiene con el medio ambiente- , podremos efectivamente escribir una historia indígena del imperio inca. Antes de pasar a estas interpretaciones más complejas y -admitámoslo- controversiales de la información contenida en los quipus, vale la pena revisar brevemente qué es lo que los investigadores entienden hoy en día con respecto a la forma en que los datos -administrativos y de otros tipos- fueron registrados en ellos.

\section{INTERPRETANDO LOS REGISTROS DE LOS QUIPUS}

La figura 2 muestra los elementos estructurales fundamentales de los quipus. $\mathrm{Su}$ «espinazo» es un cordel lineal que actúa como cordel principal. Usualmente, es la cuerda más gruesa de un quipu y está conformado por muchos grupos de hilos trenzados; usualmente a todo el conjunto se le da una torsión final en S. Un núme- 
ro variable de cordeles conocidos como colgantes están ligados al cordel principal, por lo general, con un nudo de golondrina. Los cordeles colgantes pueden tener cordeles de segundo orden a los que se conocen como subsidiarios, los que a su vez pueden también tener otros cordeles subsidiarios más. Se han identificado quipus hasta con seis niveles de cordeles subsidiarios. Los quipus pueden asimismo incluir otros elementos estructurales (Figura 2), pero los elementos más importantes son el cordel primario, los colgantes y los subsidiarios.

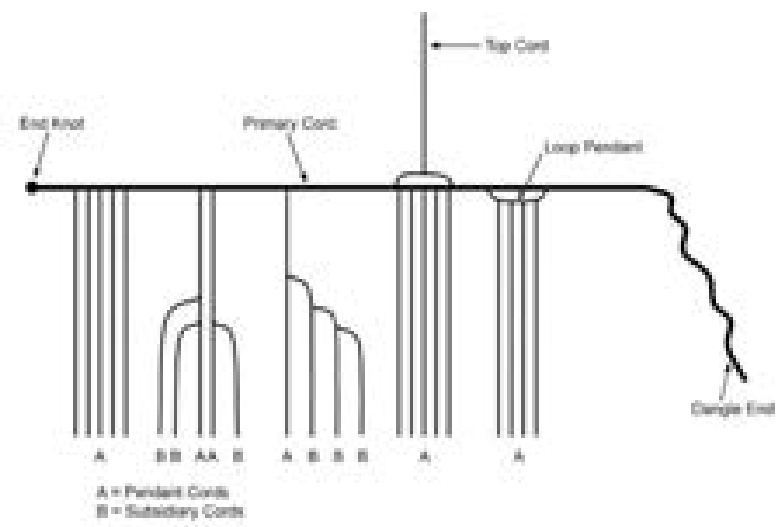

Figura 2.

Elementos estructurales comunes de un quipu. Elaboración propia.

Por lo general, se cree que los quipucamayos («fabricante/organizador/animador de nudos») que consultaban o leían un quipu lo hacían extendiendo el cordel primario entre sus manos, de modo que quedara orientado de forma paralela al suelo, en tanto que los cordeles colgantes caían verticalmente, tal como vemos en la figura 2. Podría ser que entre otras técnicas posibles para una lectura accesible, los quipus hayan sido colocados contra la pared con clavijas o algún otro artefacto o, incluso, que hayan sido extendidos entre las manos del quipucamayo y un dedo extendido del pie. 
La mayoría de los quipus tiene nudos atados en sus cordeles colgantes, subsidiarios y los de la parte superior. Los nudos más comunes son de tres tipos distintos (Figura 3): nudos de ocho (indican unidades), nudos largos (los valores entre 2 y 9) y nudos individuales (para valores decimales completos: decenas, centenas, millares, etc.). En los quipus cuantitativos organizados decimalmente, los nudos están atados en haces a distintos niveles de un registro numérico decimal de notación posicional (Figura 4). El tratamiento más exhaustivo que hasta ahora se haya realizado de las propiedades aritméticas y matemáticas del quipu es el estudio Mathematics of the Incas: code of the quipus, por Ascher y Ascher (1997). Los Ascher mostraron que las operaciones aritméticas y matemáticas empleadas por los contadores incas incluían, como mínimo, sumas, restas, multiplicaciones y divisiones; la división en fracciones desiguales y partes proporcionales, y la multiplicación de números enteros con fracciones.

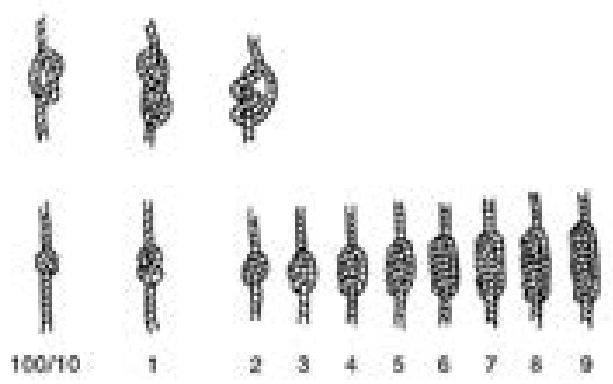

Figura 3.

Los tres tipos de nudos en los quipus decimales. Elaboración propia. 


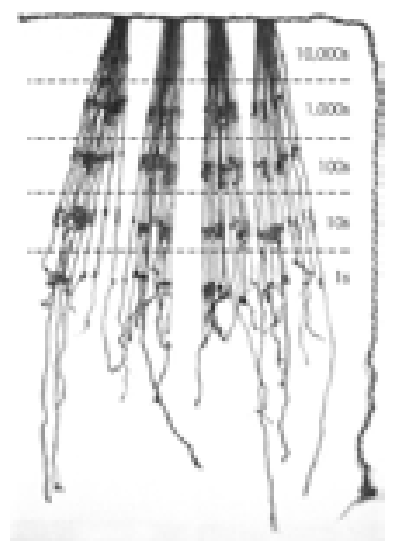

Figura 4.

Nudos atados en la jerarquía decimal. Elaboración propia.

Casi la tercera parte de todos los quipus estudiados por el proyecto de Harvard Quipu Database (KDB, base de datos de los quipus), no tienen los nudos dispuestos de modo decimal. Se cree que estos especímenes, a los que a menudo se conoce como quipus no decimales o "narrativos", contienen información codificada en alguna otra forma que aún no logra ser «leída», y que eran los que se consultaba para narrar historias, cantos, etc.

He inventariado un total de 923 quipus en museos de Sudamérica, Norteamérica y Europa. La mayoría de los ejemplares actualmente conservados en las colecciones de los museos llegaron allí hace muchas décadas y frecuentemente provenían de la excavación ilícita (esto es, el saqueo de tumbas), efectuada sobre todo a lo largo de las costas del Perú y el norte de Chile. Muchos de ellos entraron entonces al mercado ilegal de antigüedades, donde fueron comprados hace tiempo por museos o adquiridos por particulares que posteriormente los donaron a dichas instituciones. Contamos con apenas un puñado de casos en los cuales se excavó científicamente a los quipus, por ejemplo en Puruchuco, en el valle del Rímac (Urton y Brezine 2005), y en Incawasi, en la costa sur peruana (Urton y Chu 2015). 
En lo que respecta a la datación de los quipus «incas», contamos con escasa información contextual a partir de la cual intentar establecer un fechado relativo para ellos, puesto que son muy pocos los ejemplares que fueron recuperados en excavaciones científicas controladas. Hice que unos 15-20 quipus fueran fechados por medio de la espectrometría de masas (Cherkinsky y Urton 2014). Sin embargo, debido a la inestabilidad presente en la curva de calibración (es decir, la traducción de los valores de carbono 14 en fechas cercanas del calendario), alrededor del momento de la conquista hispana (1532), todas las lecturas arrojan valores con un margen muy amplio, pues abarca un periodo entre los años 1450 y 1650, esto es, jun siglo antes y uno después de la invasión española!

El quipu, como ya se indicó, fue la principal herramienta con la cual se registraba información en el estado inca. La administración estatal era atendida por un cuadro jerárquico de quipucamayos, desde los funcionarios de alto nivel que vivían en el Cusco y servían directamente al Inca y su corte, hasta los que operaban dentro de la administración imperial en lejanas capitales y centros administrativos de provincias. La administración decimal era crucial para el financiamiento del estado inca, puesto que se trataba del sistema con el cual se llevaban a cabo los censos y se supervisaba el tributo estatal, el cual era gravado bajo la forma de una leva laboral o mita (Murra 1980; 1983). En el sistema de la mita, todos los súbditos del imperio estaban obligados a trabajar en proyectos estatales cierto número de días cada mes, para lo cual se les reclutaba dentro del sistema de la administración decimal. La figura 5 es una representación esquemática de la organización de unidades laborales en el sistema tributario inca. Su disposición abarcaba desde los pequeños grupos de nivel local de diez (chunca) trabajadores en la base, hasta las agrupaciones más grandes de 10,000 (bunu) cerca de la cima. Sobre estos últimos se alzaban los jefes de provincia (tocricucs) y encima de ellos estaban los Señores de los Cuatro Cuartos (los Apus), quienes servían al Inca en el Cusco. 


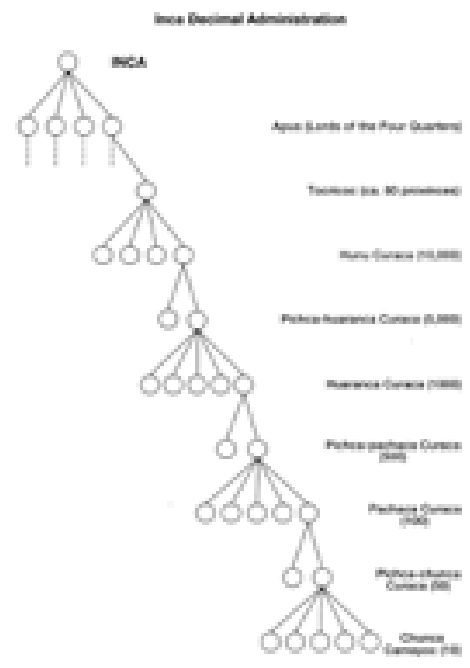

Figura 5.

La jerarquía decimal inca. Elaboración propia.

En lo que al intercambio de información sobre asuntos administrativos se refiere, la figura 5 presenta la organización fundamental de dos flujos de información distintos y recíprocos, que corren en direcciones opuestas dentro de la jerarquía administrativa decimal. Dentro de este sistema, las expectativas que los funcionarios de más alto nivel tenían con respecto a los de niveles inferiores, corrían desde la cima de la jerarquía hacia abajo. Dicha información era tal vez remitida desde los centros administrativos a lo largo del camino inca mediante chasquis (mensajeros) que llevaban quipus. La información era de naturaleza partitiva, esto es, las asignaciones encargadas a 1,000 tributarios-trabajadores eran divididas en tareas para dos grupos de 500, las cuales eran a su vez divididas en asignaciones para cinco grupos de 100 y, así, sucesivamente. En dirección inversa, los contadores en las comunidades locales remitían informes de las tareas realizadas hacia arriba, a lo largo de la cadena jerárquica de 
funcionarios. En este caso, la información en cada nivel representaba la sumatoria de cuentas provenientes del nivel inmediatamente inferior. Estos datos acumulativos eventualmente llegaban a manos de los contadores estatales en Cusco, donde se hallaba el nivel de responsabilidad más alto.

Lo que esto implica es que el curaca («señor, supervisor») de una unidad de 100 (pachaca) trabajadores notificaba a los jefes de los dos supervisores de 50 (pisca-chunca) trabajadores a su cargo, que necesitaba que cada uno de ellos reclutara un número específico de tributarios-trabajadores para un proyecto del Estado. Al final, a medida que estos dos grupos se formaban y llevaban a cabo su tarea (o inmediatamente después de ello), ambos supervisores de 50 habrían contado el número de sus respectivas cuadrillas y luego reportado dichos valores al supervisor de 100, informándole cuántos trabajadores realmente se había presentado a trabajar. En otro lugar sugerí que dado que las demandas de trabajadores que bajaban por la jerarquía probablemente eran números «ideales» o «deseados», estos valores numéricos tenderían a ser cifras redondeadas (v.g.: «necesito 50 trabajadores de cada uno de ustedes [curacas de 50]»); sin embargo, en la dirección opuesta habríamos tenido que cuando se reportaba y contaba el número de trabajadores llegados, estas serían «cifras históricas», esto es conteos reales, los cuales probablemente no habrían sido números redondos (v.g.: «42 trabajadores se presentaron [en un grupo de 50]» y «47 trabajadores se presentaron [en otro grupo de 50]»).

Quisiera, por último, señalar que los avances realizados en el análisis de los quipus nos permiten investigar cómo fue que ciertos elementos básicos de la organización social y política del Tahuantinsuyo quedaron codificados en ellos. Esto parece haberse logrado -al menos en parte- alineando y organizando los grupos de cordeles -lo que se indicaba con diferencias en su color y/o en el espacio que mediaba entre los grupos de ellos- siguiendo las categorías fundamentales según las cuales distintos grupos y tipos de personas 
quedaban organizados dentro de una comunidad. Los agrupamientos sociales incluían entidades tales como unidades domésticas, aillus y mitades. Un alineamiento semejante producía un paralelismo entre las estructuras de los quipus y las estructuras sociopolíticas que constituían la «escritura» a partir del cual un quipucamayo podía «leer» la organización social de una comunidad.

Lo que hemos presentado es un breve cuadro de cómo se registraba información en los quipus y, por ende, de cómo esta misma información estaba accesible para ser interpretada o «leída» por parte de los quipucamayos entendidos. Toda lectura de este tipo habría conformado el marco o estructura de la narrativa histórica de algún evento (v.g.: demografía, almacenamiento, tributo, etc.), tal como un quipucamayo lo habría encontrado en alguna aldea del imperio. He sostenido que tales esbozos o escrituras nos dan un bosquejo a partir del cual podemos construir una historia de los incas. Paso ahora a la cuestión de qué tipo de historia podríamos esperar encontrar en los quipus, dada la naturaleza de la información inscrita en ellos.

\section{¿QUÉ TIPO DE «HISTORIA» ES LA QUE ENCONTRAMOS EN LOS QUIPUS?}

Tal como lo sugiere el título de este artículo, mi intención es producir una historia del imperio inca y hacerlo, por vez primera en los estudios incaicos (hasta donde tengo noticia), a partir de «fuentes primarias». Con esto quiero decir, claro está, una versión de la historia incaica basada en la información proporcionada por los quipucamayos, quienes tenían un conocimiento de primera mano acerca de las instituciones, estructuras y eventos que conformaron el Tahuantinsuyo, y que ellos mismos anotaron en sus relaciones encordadas. Sin embargo, no creo que ninguna historia que podamos escribir a partir de los quipus pueda ser una historia europea basada en eventos. Con esto quiero decir que no es probable que gire en torno de personas y eventos tales como la aparición de Manco 
Cápac, el primer rey inca, y sus hermanos, en la cueva de Tambo Toco; ni tampoco de la invasión chanca, que se dice desencadenó la expansión incaica fuera del valle del Cusco, y ni siquiera de las grandes conquistas realizadas por todo el Ande por Pachacuti Inca Yupanki, el noveno inca. A decir verdad, no estoy seguro de que en los quipus tengamos registrada información basada en eventos, aun cuando tengo fuertes sospechas de que sí lo está y he argumentado vigorosamente a favor de dicho escenario (Urton 1998). Si en los registros encordados no hubiese una historia basada en eventos, sospecho que ella sí se encuentra, en cambio, en el tipo de quipu no decimal al cual he descrito en otro lugar como quipus «narrativos» (Urton 2002). El estudio exhaustivo de estos quipus tendrá que esperar a que alguien descifre íntegramente el código de este tipo particular de recuentos encordados.

Me parece que en lugar de una historia lineal de tipo europeo, basada en eventos y "grandes hombres», lo que podemos más bien producir es una versión de la historia del Tahuantinsuyo al estilo de la escritura de la historia que surgió en el temprano siglo XX en Francia, a la que se conoce como la escuela de Annales (Furet 1983). ¿Qué fue Annales y por qué sugiero que este es el tipo de historia que debiéramos tener como objetivo al interpretar los quipus incas? Lo que sugiero a continuación es que si bien es cierto que la historia de los Annales es un estilo antiguo de escribir la historia que data de la década de 1920 y que estaba poco menos que obsoleto para la década de 1990, se trata, a pesar de todo, de un tipo historiográfico notablemente idóneo para los tipos de información codificados en el gran corpus de quipus, los mismos que contienen datos administrativos, estadísticos y cuantitativos más un modesto tejido conector narrativo que mantenía todo unido.

Los fundadores de la escuela fueron los historiadores franceses Marc Bloch y Lucien Febvre. La fundación de esta tradición historiográfica quedó marcada, en 1929, con la publicación del primer número de una revista titulada Annales (Furet 1983). Esta fue 
la culminación de tendencias anteriores de larga data en los estudios científicos históricos y sociales franceses que se remontaban hasta comienzos del siglo XX. Jacques Revel sostiene que La méthode historique appliquée aux sciences sociales, de François Simiand (1903), es el texto fundacional. Además de hacer sonar la alerta tempranamente contra la historia narrativa positivista basada en eventos, Simiand sostuvo allí que la historia debía colocarse al centro de las ciencias sociales (Revel 1978: 11-12). Para él, los objetivos de este tipo de escritura de la historia sería producir «historias totales» $-\mathrm{y}$ no solamente la historia de la política y de los grandes hombres- así como recurrir y contribuir ampliamente a diversos campos dentro de las ciencias sociales. La noción rectora era que «la historia ya no cabe íntegramente dentro de un constructo genealógico, en el cual acontecimientos anteriores explican los posteriores, los que deben en consecuencia ser reconstituidos prestando minuciosa atención hasta sus más remotos orígenes. En efecto, la historia solía ser una forma de aprendizaje que vivía obsesionada con los orígenes» (Furet 1983: 395).

La historia de los Annales se opuso desde sus primeros años a las tradicionales historias narrativas lineales que tenían como modelo a la historia política, en la cual el estado-nación (europeo) y sus elites (masculinas) eran los principales actores y agentes del cambio. En lugar de escribir historias lineales y narrativas, su enfoque:

Prefers to analyze deeper trends rather than superficial changes, to study collective behavior rather than individual choices, to examine economic and social determinants rather than institutions or governmental decisions. Thus demography, economics, and sociology have taken over a field increasingly deserted by its traditional inhabitants: kings, notables, nations and the theater of power around which they never ceased to gravitate. ${ }^{2}$

2 «Prefiere analizar tendencias profundas antes que cambios superficiales, estudiar el comportamiento colectivo antes que opciones individuales, examinar determinantes económicos y sociales antes que instituciones o decisiones gubernamentales. De este modo la demografía, la economía y la sociología han tomado un campo abandonado cada vez más por sus habitantes tradicionales: reyes, 
Al historiador francés Fernand Braudel se le atribuye haber llevado la historia de Annales a su cumbre más elevada, especialmente con sus dos obras monumentales: El Mediterráneo y el mundo mediterráneo en la época de Felipe II (1972 [el original francés es de 1949, con una segunda edición revisada y ampliada en 1966; la primera edición en español es de 1953, la segunda de 1976]) y los tres volúmenes de Civilización material y capitalismo: siglos XV-XVIII (1981 [el original francés es de 1967-1979], la edición en español es de 1993). En El Mediterráneo, Braudel inició un estudio de Felipe II, pero terminó con un examen más amplio del mundo mediterráneo en el siglo XVI. Aún más importante para lo que nos interesa aquí es que él «rejected the influence of the individual on history, and hence much of the significance of political history, in favour of an interpretation based on a consideration of physical and material constraints, one in which the individual was subsumed by the environment» (Hufton 1986: 209). ${ }^{3}$

Tal como Hufton señala, los personajes de la historia del Mediterráneo de Braudel son «grain and cereal crops, desase, technology and transport, money, housing and clothing» (1986: 211). ${ }^{4}$ Salvo por el dinero, se trata de temas que no son del todo ajenos al tipo de realidades que he mencionado en este trabajo. Por otro lado, el énfasis que Braudel le prestó al Mediterráneo como actor, hizo que el enfoque historiográfico de los Annales resultase particularmente apropiado para los historiadores y antropólogos que estudian los Andes. El gran escenario andino -representado por la gama de medioambientes y terrenos que se extienden desde los desiertos

notables, naciones y el teatro del poder alrededor del cual jamás cesaron de gravitar» (la traducción es nuestra) (Furet 1983: 399).

3 «Rechazó la influencia del individuo en la historia y por ende gran parte de la importancia de la historia política, y favoreció una interpretación basada en la consideración de restricciones físicas y materiales, en la cual el individuo quedaba subsumido por el medio ambiente» (la traducción es nuestra).

4 «Los cultivos de granos y cereales, las enfermedades, la tecnología y el transporte, el dinero, la vivienda y la vestimenta» (la traducción es nuestra). 
costeros del Pacífico hasta las cumbres de los Andes, descendiendo luego a los bosques tropicales del Amazonas- ha tenido un papel significativo en la construcción de las relaciones etnohistóricas y antropológicas de las civilizaciones andinas del pasado y el presente.

En efecto, el término con el cual a menudo se menosprecia el enfoque histórico de algunos estudiosos de las sociedades andinas -lo andino-, conlleva la idea que dichos investigadores han sido engatusados por el medio ambiente andino (tal como Braudel lo fue por «lo mediterráneo») y han proyectado una noción de inercia histórica sobre estas sociedades, la cual asume la forma de «continuidades culturales». Según esta caricatura, dichos investigadores imaginan supuestamente que las sociedades andinas son rígidas, estáticas e invariables y que lo son desde un pasado lejano. Me parece que esta afirmación -que en esencia afirma que todo antropólogo o etnohistoriador que reconoce y explora el significado y la importancia de las similitudes existentes entre las sociedades y culturas de los Andes del pasado y el presente estaría negando toda posibilidad de cambio- delata en sí misma una ceguera deliberada ante los procesos sociales y culturales de la persistencia y el cambio. Algo debe caber entre la celebración que Braudel hiciera del actuar del Mediterráneo y el menosprecio por los (etno)historiadores andinos, que de igual modo ven que el entorno ambiental también tiene un papel, aunque ciertamente no uno determinante.

La otra gran contribución que Braudel hiciera a la tradición de los Annales, además de haber retirado al individuo de los reflectores de la historia total y de haber intentado colocar a todas las ciencias sociales dentro del ámbito de la historia, fue el haber establecido una nueva forma de comprender el ritmo o la escala del tiempo histórico. Es aquí que los estudiosos de los Andes pueden recurrir más fructíferamente a los Annales, al evaluar la información registrada en los quipus como material para una historia del imperio inca. 
Braudel desarrolló una construcción temporal que tenía como base dejar de lado al así llamado «tiempo normal» -horas, semanas, años y siglos- y dividirlo en un esquema tripartito conformado por tres tipos de tiempo. Estos eran el tiempo largo, que es un tiempo virtualmente ilimitado que se extiende a lo largo de muchos siglos en los cuales la existencia humana virtualmente no ha cambiado (Braudel mismo se interesaba por la longue durée en la historia del Mediterráneo, desde el siglo XV hasta fines del XVIII); el tiempo medio, al cual usualmente se conoce en inglés y español como la coyuntura, y que en el tiempo normal abarca por lo general del orden de unos cincuenta años a un siglo y que, a menudo, coge el tiempo de un ciclo comercial o un cambio demográfico o algún otro ciclo de cambio; y la corta duración o acontecimiento, que puede referirse a fenómenos tales como una cosecha buena o mala, a depresiones industriales breves o a dislocaciones temporales, provocadas tal vez por una guerra o algún acontecimiento similar (Hufton 1986: 210-11).

El esquema tripartito de Braudel no solamente brindó una nueva organización temporal a la narrativa de los historiadores; sino que el ritmo o la escala a la cual tenían lugar los cambios pasó ahora a ser la cuestión central, así como el reconocimiento de una jerarquía de valor dentro del flujo de la historia. Esto implicaba aceptar que ciertos elementos de la sociedad, sus instituciones, formas de organización, etc., eran fundamentales y solamente cambiaban con suma lentitud cuando lo hacían (esto es, los elementos de larga duración, que Braudel asoció con la estructura, la semiinmovilidad alrededor de la cual todo gravita) (Braudel 1968: 74), en tanto que ciertas incidencias históricas eran acontecimientos breves de corta duración e importancia inmediata y local. Entre estos extremos tenían lugar las coyunturas, fases o ciclos más largos en los cuales la sociedad se transformaba a un ritmo que podía seguirse a lo largo de periodos perceptibles y dentro de ciclos mensurables. El reto del historiador era identificar y dar cuenta de todos estos tres tipos, sin verse seducido, por ejemplo (como la mayoría de los historiadores 
acostumbraba), por los acontecimientos de corto plazo. Braudel presentó este reto del siguiente modo:

...para quien pretenda captar el mundo, se trata de definir una jerarquía de fuerzas, de corrientes y de movimientos particulares; y más tarde, de recobrar una constelación de conjunto. En cada momento de esta investigación, es necesario distinguir entre momentos largos y empujes breves, considerados estos últimos en sus fuentes inmediatas y aquellos en su proyección de un tiempo lejano (Braudel 1968: 76).

Esta tripartición del tiempo histórico puede resultar extremadamente útil para los estudios de los quipus, para así evaluar la importancia histórica y las valoraciones jerárquicas diferenciales de los datos registrados en ellos.

\section{Apuntes para una historia del Tahuantinsuyo al estilo de ANNALES}

El punto central de mi examen en este artículo es que los quipus $-\mathrm{O}$ al menos su forma administrativa - registraban datos cuantitativos, estadísticas. Este es el tipo de material con el que todo historiador seguidor de los Annales que se respete estaría complacido de recibir, como base para escribir historia. Me parece que los andinistas -al menos aquellos a los que nos interesa intentar comprender o «descifrar» los quipus- hemos lamentado durante demasiado tiempo la falta de materiales «históricos», cuando podíamos contar con la interpretación de las cuentas guardadas en los quipus.

La idea de una historia al estilo de los Annales me mueve a preguntarme: ¿tal vez hemos estado buscando en el lugar errado y hemos, por ello, subestimado la información con la que contamos en estas maravillosas «melenas encordadas»? En verdad que eso es lo que hemos hecho hasta ahora, pero si cambiamos nuestra forma de pensar acerca de la información con la que sí contamos y la si- 
tuamos dentro de un paradigma historiográfico que pueda escribirse con los datos disponibles (esto es, estadísticas administrativas), podremos en efecto escribir una historia del Tahuantinsuyo con datos que existen hoy a nuestra disposición. ¿Cómo sería una historia de ese estilo? Es decir, ¿qué tipo de información está disponible en los quipus? A continuación daré un ejemplo de esto. Lo importante a señalar con respecto a este ejemplo es que está conformado por unidades mayormente inconexas de datos, ítems o unidades de información descriptivas acerca de este lugar o circunstancia o estatus, para los cuales el lector del quipu debía proporcionar los detalles y la armazón gramatical, y así producir una narrativa histórica a partir de la información inscrita. En suma, sostengo que las cuentas de los quipus no eran ni una mnemotécnica -conformada por marcadores de posición vacíos para información retenida íntegramente en la memoria de los quipucamayos, como a menudo se ha sostenido-, ni tampoco parecen contener relaciones plenamente gramaticales de circunstancias históricas, como yo alguna vez sostuve en un artículo anterior (Urton 1998). Estas relaciones más bien caen en algún lugar en medio de estos dos extremos del registro de narrativas.

Presento aquí información tomada de uno de mis primeros estudios de un quipu proveniente de Atarco, en la costa sur peruana, y sugiero cómo la información registrada en él podría haber sido «leída» o actuada, en una performance narrativa dada por un quipucamayo.

\section{Un quipu del tributo proveniente de Atarco, costa sur PERUANA}

Tomo este ejemplo de mi estudio de un quipu actualmente en el Museum für Völkerkunde en Munich, Alemania, al cual llamaré 
UR28. ${ }^{5}$ El quipu tiene 74 cordeles colgantes, todos los cuales, salvo por un puñado de ellos, son de color marrón claro (AB) o mediano (MB). Los 74 cordeles están organizados en grupos: Grupo $1=$ cordel \#1, Grupo 2 = cordeles \#2-4; y Grupo 3 = cordeles \#5-74. El cordel \#1, que es de color marrón claro (AB), está anudado con nudos cuyos valores suman 102. La organización de los cordeles se muestra de modo esquemático en la figura 6.

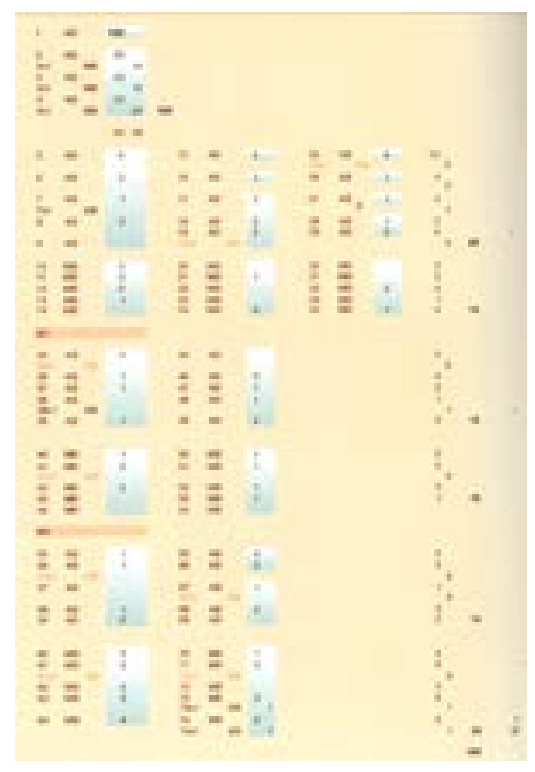

Figura 6.

Organización esquemática de los datos en UR28.

5 Vaya mi agradecimiento a Helmut Schindler por su ayuda y generosa hospitalidad durante las dos semanas que pasé en el Museum für Völkerkunde, Munich, durante el verano de 2004. Quisiera asimismo manifestar mi profundo aprecio a Carrie Brezine, quien me proporcionó el desglose y el análisis estructural inicial del quipu UR28. Brezine era, en ese entonces, la administradora del proyecto Quipu Database. La interpretación más a fondo y el análisis de dicho quipu, en la forma aquí presentada, es obra del autor. 
En cuanto a los cordeles del Grupo 2, cada uno de los tres (= $\# 2,3,4)$ tiene un cordel subsidiario (= \#2s1, 3s1, 4s1). Los colores y valores en nudos de estos tres cordeles y sus subsidiarios están dados en el cuadro 1. Como vemos, los valores anotados en nudos en los cordeles \#2-4 y sus subsidiarios suman 102, el mismo valor del cordel \#1.

\begin{tabular}{|c|c|c|c|}
\hline $\begin{array}{l}\text { Cordel } \\
\# 2=\end{array}$ & Subsidiario & $\begin{array}{c}\text { Color } \\
\text { AB }\end{array}$ & $\begin{array}{c}\text { Valor } \\
29\end{array}$ \\
\hline & $\# 2 \mathrm{~s} 1=$ & MB & 14 \\
\hline$\# 3=$ & & $\mathrm{AB}$ & 13 \\
\hline & $\# 3$ s1 $=$ & MB & 10 \\
\hline$\# 4=$ & & $\mathrm{AB}$ & 12 \\
\hline & $\# 4 \mathrm{~s} 1=$ & MB & 24 \\
\hline
\end{tabular}

Cuadro 1.

Los colores de los cordeles y los valores en nudos de los cordeles 2-4. Quipu UR28

No tenemos espacio para mostrar detenidamente la organización de los colores y valores de los cordeles entre los 70 que conforman el Grupo 3 (esto es, los cordeles \#5-74; véase Urton 2010). Resumiendo, los 70 cordeles que conforman el Grupo 3 están organizados en seis agrupaciones, tres de las cuales son de cordeles de color marrón claro (AB) y las otras tres marrón mediano (MB). Cuando sumamos los totales de los nudos de las seis agrupaciones del Grupo 3 tenemos el mismo total (con un error) ${ }^{6}$ que los que

6 Está claro que hay un error de registro ya sea en el cordel \#4 (=12) o en los grupos de cinco cordeles (\#55-\#59) + (\#65-\#69), que suman 14. Tengo fuertes sospechas de que el error se encuentra en este último agrupamiento de cordeles, y que la suma planeada de esta última pareja de agrupaciones "impares" de cinco cordeles debiera ser 12 (como en el cordel \#4), y no 14. De aceptar esta explicación acerca de la ubicación donde se encuentra el error, veremos que el valor de 102, que figura tanto en el cordel \#1 como en la suma de los valores en los cordeles \#2-\#4, se repite en las agrupaciones de cordeles desde el cordel \#5 hasta el \#74. 
mostramos arriba en el cuadro 1 , esto es $(54+48=) 102$. Tres de las agrupaciones de cordeles del Grupo 3 son $\mathrm{AB}$ y tienen los mismos valores que las tres cuerdas $\mathrm{AB}$ del cuadro 1; las otras tres agrupaciones de cordeles del Grupo 3 son $\mathrm{MB}$ y tienen los mismos valores que los tres cordeles MB del cuadro 1.

De este modo: a) cada una de las tres agrupaciones de cordeles que conforman el quipu UR28 contiene el valor numérico 102; y b) los cordeles de los Grupos 2 y 3 están divididos en seis grupos o conjuntos, la mitad de los cuales son $\mathrm{AB}$ y la otra mitad MB; los valores numéricos anudados en las seis agrupaciones de cordeles de los Grupos 2 y 3 son idénticos (salvo por el error indicado en la nota \#2). Es importante señalar que cuando el valor anotado en un solo cordel -esto es, el cordel \#1- es 102, su color es el marrón claro (AB). Sostengo por ello que AB es la cualidad o valor del color dominante e inclusiva (véase más adelante).

El total de la cuenta-resumen registrado en los tres agrupamientos de cordeles de UR28 - esto es, 102- resulta interesante en relación con los valores censales incas. Numerosas fuentes coloniales hispanas nos dicen que en los censos del Estado inca, la pachaca («un ciento»), un grupo conformado por 100 tributarios trabajadores (esto es, de mita), fue uno de los principales agrupamientos que organizaban a las poblaciones sometidas (véase la figura 5). Sostengo que el quipu UR28 contiene la contabilidad de seis aillus divididos en dos mitades (probablemente hanan «superior», y hurin «inferior»), las cuales se encuentran indicadas por una diferencia de color (AB vs. MB), y que la cuenta total registrada en este quipu conformaba una pachaca de trabajadores en la jerarquía decimal inca. Dado que el quipu solamente registra el número de tributarios cabezas de familia en los seis aillus divididos en dos mitades, podemos multiplicar el número 102 por un factor de 5 -un valor común para el tamaño de los tributarios en relación con las unidades domésticas usado por los demógrafos (Cook 1981)-, para llegar así a un estimado de la población total de este pueblo, que habría sido de alrededor de 510 . Por último, dado que el color del valor 102 anotado en un único 
cordel es $\mathrm{AB}$, concluyo que este fue el término, valor o identidad de color de hanan, la mitad superior alta.

En suma, un quipucamayo habría podido «leer» la siguiente narrativa -o probablemente una versión más ampulosa, detallada y políticamente dramática- en UR28, el quipu de Atarco:

Runacuna [«pueblo»], vengo ante ustedes para reportar las condiciones y disposición de la comunidad de Atarco, en el valle de Nazca, Cuntisuyu [el cuadrante sudoccidental del Tahuantinsuyo]. Esta comunidad tiene una población total de 510 personas, suma dividida en dos partes [sayas], hanan (marrón claro) y hurin (marrón mediano). El número total de trabajadores de la mita disponibles para servir al Inca en esta comunidad es de 102 hombres.* Cada saya/mitad está conformada por tres aillus. Los tres aillus de hanan Atarco contienen el siguiente número de trabajadores de la mita: 29, 13 y 12. Los tres aillus de hurin Atarco contienen el siguiente número de trabajadores de la mita: 14,10 y 24 . Estos números fueron registrados y su exactitud verificada dos veces en el quipu que tengo ante mí. En la vida ceremonial y ritual de esta comunidad el primer grupo de tres aillus, los de hanan Atarco, habrá de tener precedencia y prioridad sobre el segundo grupo de tres aillus, los de hurin Atarco. La paz sea con el Sapa Inca.

\section{Conclusiones}

Mi supuesto es que si fuésemos capaces de leer los quipus, un porcentaje sumamente alto contendría el tipo de información registrado en UR28, tal como la hemos interpretado. Es más, me parece que los «anales del Tahuantinsuyo» potencialmente contenían miles de tales informes de comunidades de todo el imperio, desde el actual Ecuador hasta el centro de Chile. De ser esto correcto, ello sugiere que una alta proporción de los registros indígenas referidos a la historia del Tahuantinsuyo se ocupaban de asuntos tales como las estructuras sociales (v.g. mitades, aillus y 
unidades de la organización decimal) y el perfil demográfico de las comunidades subordinadas al Inca. Informes de nivel local de este tipo habrían sido enviados desde comunidades como la de Atarco hasta los centros administrativos regionales, donde habrían sido revisados por quipucamayos de un nivel más alto. Los informes provenientes de múltiples comunidades habrían sido entonces combinados, y los informes englobados habrían llegado en última instancia al Cusco, la capital.

La pregunta central a la que nos enfrentamos cuando intentamos comprender los registros incas es si, en última instancia, lo que interesaba a sus quipucamayos a la hora de preparar y mantener registros para la «historia» del Tahuantinsuyo se refería esencialmente a la estructura, la demografía y las estadísticas económicas (v.g.: los registros del contenido de los depósitos; véase Urton y Chu 2015). Según esta postura, los grandes archivos de quipus de que hablan los cronistas (Zárate 1944: 28) habrían sido esencialmente masivos compendios de estadísticas, o aritmética política. De otro lado, tal vez un número significativo de los quipus habría registrado lo que en Occidente reconoceríamos como anales históricos, esto es las relaciones narrativas de los reyes Incas, las reinas y la historia de su vida.

Estos pensamientos y preguntas referidos a la naturaleza de las fuentes históricas en el Tahuantinsuyo nos suscitan una reflexión en torno a las nociones occidentales tradicionales de qué constituye una historia - esto es, relaciones basadas en acontecimientos que narraban los hechos de los grandes hombres y mujeres y las causas que subyacen a las transformaciones históricas-, pues cabe plantearse si tales nociones fueron o no compartidas por los incas. Tal vez se interesaban más por la estructura, la demografía y las estadísticas económicas, dejando a los grandes narradores la retención en su memoria de las historias de vida de los reyes y reinas. Si los registros históricos incas estaban conformados fundamentalmente por los tipos de información aducidos en nuestro ejemplo, proveniente del quipu UR28, entonces quisiera sugerir que el paradigma historiográfico desarrollado por los historiadores de Annales a mediados 
del siglo XX en Francia y otras partes de Occidente podría brindarnos la perspectiva más apropiada y las herramientas más eficaces e idóneas para escribir la historia del Tahuantinsuyo.

\section{REFERENCIAS}

Ascher, Marcia y Robert Ascher

1997 Mathematics of the Inca: Code of the Quipu. Nueva York: Dover.

BRAUDEL, Fernand

1968 La historia y las ciencias sociales. Madrid: Alianza Editorial.

Cherkinsky, Alexander y Gary Urton

2014 «Radiocarbon chronology of Andean quipus». Open Journal of Archaeometry, vol. 2: 5260, pp. 32-36.

Cook, Noble David

1981 Demographic Collapse: Indian Peru 1520-1620. Cambridge: Cambridge University Press.

Curatola Petrocchi, Marco y José Carlos de la Puente Luna (ed.)

2013 El quipu colonial: estudios y materiales. Lima: Pontificia Universidad Católica del Perú.

FuRET, Francois

1983 «Beyond the Annales». The Journal of Modern History, vol. 55, n. 3, pp. 389-410.

Hufton, Olwen

1986 «Fernand Braudel». Past \& Present, n. 112, pp. 208-213.

LOCKE, L., Leland

1923 The Ancient Quipu, or Peruvian Knot Record. Nueva York: American Museum of Natural History.

MAcCormack, Sabine

2007 On the Wings of Time: Rome, the Incas, Spain, and Peru. Princeton: Princeton University Press. 
Murra, John V.

1980 The Economic Organization of the Inca State [1956]. Greenwich, CT: JAI Press.

1983 «La mit’a al Tahuantinsuyo: prestaciones de los grupos étnicos». Chungará: Revista de Antropología Chilena, vol. 10, pp. 77-94.

Pereyra S., Hugo

2006 Descripción de los quipus del Museo de Sitio de Pachacamac. Lima: Universidad Nacional Mayor de San Marcos.

ReVel, Jacques

1978 «The Annales: Continuities and Discontinuities». Review (Fernand Braudel Center), vol. 1, n. 3-4, pp. 9-18.

Simiand, François

1903 «Méthode historique et science sociale». Revue de synthèse historique, París, n. 6.

URTON, Gary

1998 «From Knots to Narratives: Reconstructing the Art of Historical Record-Keeping in the Andes from Spanish Transcriptions of Inca Quipus». Ethnohistory, vol. 45, n. 3, pp. 409-438.

2002 «Recording Signs in Narrative-Accounting Quipus». En: J. Quilter y G. Urton (eds.). Narrative Threads: Accounting and Recounting in Andean Quipu. Austin: Universiry of Texas, pp. 171-196.

2003 Signs of the Inca Quipu: Binary Coding in the Andean Knotted-String Records. Austin: University of Texas.

2017 Inca History in Knots: Reading Quipus as Primary Sources. Austin: University of Texas.

UrTon, Gary y Carrie J. Brezine

2005 «Quipu Accounting in Ancient Peru». Science, n. 309, pp. 1065-1067.

URTON, Gary y Alejandro Chu

2015 «The Incawasi Quipu Archive: An Inca State Storage Facility and Accounting Center on the South Coast of Peru». Latin American Antiquity, n. 26, pp. 512-529.

Zárate, Agustín de

1944 [1555] Historia del Descubrimiento y Conquista del Perú. Edición revisada, con anotaciones y concordancias de Jan M. Kermenic. Lima: Librería e Imprenta D. Miranda. 